Research Article

\title{
Fabrication of ABS/Graphene Oxide Composite Filament for Fused Filament Fabrication (FFF) 3D Printing
}

\author{
C. Aumnate $\mathbb{D}^{1},{ }^{1}$ A. Pongwisuthiruchte $\mathbb{D}^{2,3}$ P. Pattananuwat $\mathbb{D}^{2,3}$ and P. Potiyaraj $\mathbb{D}^{1,2,3}$ \\ ${ }^{1}$ Metallurgy and Materials Science Research Institute, Chulalongkorn University, Bangkok, Thailand \\ ${ }^{2}$ Department of Materials Science, Faculty of Science, Chulalongkorn University, Bangkok, Thailand \\ ${ }^{3}$ Center of Excellence on Petrochemical and Materials Technology, Chulalongkorn University, Bangkok, Thailand
}

Correspondence should be addressed to C. Aumnate; chuanchom.a@chula.ac.th

Received 6 August 2018; Revised 26 September 2018; Accepted 8 October 2018; Published 6 November 2018

Academic Editor: Amit Bandyopadhyay

Copyright ( $\odot 2018$ C. Aumnate et al. This is an open access article distributed under the Creative Commons Attribution License, which permits unrestricted use, distribution, and reproduction in any medium, provided the original work is properly cited.

Additive manufacturing, the so-called three-dimensional (3D) printing, is a revolutionary emerging technology. Fused filament fabrication (FFF) is the most used 3D printing technology in which the melted filament is extruded through the nozzle and builds up layer by layer onto the build platform. The layers are then fused together and solidified into final parts. Graphene-based materials have been positively incorporated into polymers for innovative applications, such as for the mechanical, thermal, and electrical enhancement. However, to reach optimum properties, the graphene fillers are necessary to be well dispersed in polymers matrix. This study aims to emphasise the interest of producing ABS/graphene oxide (GO) composites for 3D printing application. The ABS/GO composite filaments were produced using dry mixing and solvent mixing methods before further melt extruded to investigate the proper way to disperse GO into ABS matrix. The ABS/GO composite filament with 2 wt.\% of GO, prepared from the solvent mixing method, was successfully printed into a 3D model. By adding GO, the tensile strength and Young's modulus of ABS can be enhanced. However, the ABS/GO composite filament that was prepared via the dry mixing method failed to print. This could be attributed to the aggregation of GO, leading to the die clogging and failure of the printing process.

\section{Introduction}

Numerous 3D printing technologies are now accessible, such as stereolithography apparatus (SLA), selective laser sintering (SLS), laminated object manufacturing (LOM), and fused filament fabrication (FFF). The FFF is considered to be the most commonly used and well-recognized technology for making functional prototypes. In the FFF technique, a thermoplastic filament is melted and extruded through the nozzle, building up layer by layer onto the platform or build plate. The layers are then fused together and solidified into final products. Consequently, the quality of the printed parts can be controlled by adjusting the printing parameters, such as layer height, printing temperature, printing speed, and printing orientation [1-6]. 3D printed polymers are used in various areas, for example, in automotive, architectural, and even in medical fields. Due to the relatively simple design, capability, and affordability of the FFF process, it has gained significant attention in both industry and academic research [5]. However, the usable materials are limited to thermoplastic polymers with appropriate melt viscosity. As a result, the melt viscosity should be adequate to allow extrusion, at the same time, suitable to provide structural supports $[4,6]$. Even though the $3 \mathrm{D}$ printing technologies have attracted much attention over the past years, most of the published studies focused on the printing of pure polymer materials. The 3D printed polymer products are now used as conceptual prototypes rather than functional components because of their shortage in strength and limited functionality. Thus, there are recently extensive studies on developing printable polymer composites with improving the performance and gaining excellent functionalities [7-9]. For example, Bandyopadhyay et al. [2] used the FFF technique to fabricate the polymer/ceramic composites with controlled phase structures, which are not possible with the conventional fabrication techniques. 
Polymer/nanofiller composites have been considerably investigated due to their broad applications. However, they have many drawbacks regarding the agglomeration or nonuniform dispersion of reinforcements or fillers. Also, the voids generated during the composite filaments fabrication can lead to the properties' defection. In general, the addition of nanofillers results in enhancing the mechanical, electrical, thermal, and optical properties of the matrix. Likewise, GO delivers relatively high mechanical strength, thermal conductivity, and electrical properties $[8,10,11]$. If the GO sheets are well dispersed in the polymer matrix, they can form a highly oriented microstructure or cocontinuous networks in the polymer, resulting in the mechanical, thermal, and electrical properties improvement [12]. Graphene-based composite is still challenged due to its poor dispersity, which may be caused by various reasons such as restacking of the GO, weak interfacial bonding, and incompatibility with polymer matrix $[10,13]$. Pinto et al. [10] incorporated a small amount $(0.2$ to $1 \mathrm{wt} . \%)$ of graphene oxide (GO) and graphene nanoplatelets (GNP) into poly (lactic acid), PLA, to produce composite films with improved mechanical performance and oxygen and nitrogen permeability. Wang et al. [14] reported that the tensile strength of the PVA/GO composite nanofibers increased by 42 times with addition of only a slight loading of GO (0.02 wt.\%). Lin et al. [15] fabricated polyethylene/graphene oxide nanocomposites by the melt blending technique using polyethylene-grafted graphene oxide as a compatibilizer. Even though a relatively good dispersion of graphene oxide in the polyethylene matrix was evidenced, the improvement of mechanical properties was still limited. The resulted graphene-based composites can be suitable for various applications such as architectural applications like patio roofs, windows, and trim [16].

There are three typical methods for graphene-based polymer composite fabrication methods, including in situ polymerization, melt compounding, and solvent blending. The critical challenge for efficiently reinforcing the graphene-based polymer composite is the good dispersion of graphene fillers, which is significantly influenced by the fabrication techniques. Even though many reports stated that the melt extrusion or melt-compounding process is the most typically used methods, the GO cannot be homogeneously dispersed in the polymer matrix. Due to the high surface area of $\mathrm{GO}$, it is tough for the molten polymer to cover the two sides of the fragile GO sheets effectively. As a result, the stack or agglomeration of GO sheets can be observed [10, 11].

Zhang et al. [17] fabricated the flexible circuits based on reduced GO ( $\mathrm{r}-\mathrm{GO}$ ) using the FFF $3 \mathrm{D}$ printing technique. They reported that the orientation of $\mathrm{r}-\mathrm{GO}$ occurred during the extrusion process contributed to enhancing the conductivity of the 3D printed composite parts. Moreover, Dul et al. [18] successfully prepared the ABS/GNP composite for the FFF process using the melt compounding method. The presence of GNP led to the reduction in the coefficient of thermal dilation and improved the stability under longlasting loads for the $3 \mathrm{D}$ printed parts. However, it has been spotted that the polymer/graphene-based material composites prepared via the solution mixing method provided better electrical properties than those fabricated by melt extrusion due to the better dispersion of graphenebased materials in polymer solution $[16,19]$.

Acrylonitrile butadiene styrene (ABS) is one of the most used materials in the FFF process [20]. The relatively low glass transition temperature $\left(T_{\mathrm{g}}\right)$ and excellent processing properties of ABS led to the ease of filament extrusion and $3 \mathrm{D}$ printing. Moreover, it is an amorphous polymer, which means there is no crystallite. Accordingly, the shrinkage ratio during the cooling process is small, offering the high printing accuracy and the dimensional constancy. All of the characteristics stated above make ABS as an outstanding material for FFF 3D printing. Incorporation of graphene-based materials will potentially enlarge the applications and functionalities of the $3 \mathrm{D}$ printed $\mathrm{ABS}$, in particular, some practical applications such as auto parts, conceptual prototypes, and jigs. However, the use of $\mathrm{ABS} /$ graphene-based composites in $3 \mathrm{D}$ printing application is still rarely demonstrated. Wei et al. [13] successfully demonstrated one of the first attempts to $3 \mathrm{D}$ print ABS/graphene composites using solution-based process. However, there was no report regarding the property investigation for such $3 \mathrm{D}$ printed composites.

To produce a good-quality filament for the FFF process, critical melt extrusion process parameters need to be examined. This study aims to accomplish good-quality composite filament from ABS/GO composites. The ABS/GO composites are prepared via solution mixing and dry mixing methods, followed by melt extrusion to achieve the good GO dispersion. The processability of $\mathrm{ABS} / \mathrm{GO}$ composites is further investigated in terms of thermal properties and rheological properties. Also, 3D objects are printed to explore the printability of the prepared ABS/GO filament.

\section{Materials and Methods}

2.1. Preparation of Graphene Oxide (GO). The GO was prepared using Hummers' method. Concentrated $\mathrm{H}_{2} \mathrm{SO}_{4}$ was added to a mixture of graphite flakes (1 wt.\% equiv.) and $\mathrm{NaNO}_{3}$ (0.5 wt.\% equiv.). Then, the mixture was cooled to $0^{\circ} \mathrm{C}$, and $\mathrm{KMnO}_{4}$ (3 wt.\% equiv.) was added slowly in portions to keep the reaction temperature below $20^{\circ} \mathrm{C}$. After that, the reaction was warmed to $35^{\circ} \mathrm{C}$ and stirred for 30 minutes, at which time water was added slowly to produce a sizable exothermic reaction to $98^{\circ} \mathrm{C}$. The external heating was also introduced to maintain the reaction temperature at $98^{\circ} \mathrm{C}$ for 15 minutes. Then the heat was removed, and the reaction was cooled down in a water bath for 10 minutes. From this step, additional water $(420 \mathrm{ml})$ and $30 \% \mathrm{H}_{2} \mathrm{O}_{2}$ ( $3 \mathrm{ml}$ ) were added, and then the mixture was cooled down to room temperature, followed by multiple washing, and dispersed in water.

2.2. Preparation of ABS/GO Composite. The dispersed GO in water was washed and replaced by DMF to obtain a homogeneous GO/DMF dispersion with 2 wt.\% of GO in DMF. The ABS was then dissolved in DMF to get $10 \mathrm{wt} . \%$ of ABS in DMF. Then, the GO/DMF dispersion and ABS/DMF solution were mixed and sonicated for 2 hours. The mixture 
was then dried to obtain ABS/GO composite with 20 wt.\% GO.

\subsection{Preparation of ABS/GO Composite Filament}

2.3.1. Solution Mixing. In this method, the ABS gets dissolved, and the GO is dispersed in DMF. Then, the dispersed GO and ABS solution is mixed. The ABS/GO composite is obtained after solvent evaporation, which further combined with pure $\mathrm{ABS}$ and extruded to produce $\mathrm{ABS} / \mathrm{GO}$ filament for FFF 3D printing.

2.3.2. Dry Mixing. ABS is mixed mechanically with GO powder and then is melt compounded using the twin-screw extruder to avoid the use of the solvent system. This method is widely used for preparing thermoplastic nanocomposite.

For the filament extrusion process, the ABS/GO composite with $20 \mathrm{wt} . \%$ of GO content was diluted to $4 \mathrm{wt} . \%$ of GO by mixing with the neat ABS granules. The mixture was then melted and extruded using the twin-screw extruder. The extrusion temperatures ranged from $160^{\circ} \mathrm{C}$ to $210^{\circ} \mathrm{C}$ from the hopper to the die. Thus, the $1.75 \mathrm{~mm}$ diameter filament was produced and collected for the $3 \mathrm{D}$ printing test. Figure 1 demonstrates the equipment setup for preparing the ABS/GO filament by the melt extrusion process.

2.4. Fabrication of $3 D$ Printed Parts. An open source 3D printer, WANHAO Duplicator 6, was used to fabricate the 3D specimens. A tensile test specimen was designed using CAD software based on ASTM D638-10 [21]. The FFF printing parameters were optimized and are listed in Table 1. It is noted that the same printing parameters were used for both pure $\mathrm{ABS}$ and $\mathrm{ABS} / \mathrm{GO}$ composite filaments.

\subsection{Characterization}

2.5.1. X-Ray Diffraction (XRD) Analysis. The X-ray diffraction (XRD) of graphene-based materials was performed using an X-ray diffractometer (Bruker AXS Model D8 Discover). All samples were scanned over the range $2 \theta=2-50^{\circ}$, and measurements were recorded at every $0.02^{\circ}$ interval.

2.5.2. Differential Scanning Calorimetry (DSC). The measurements were carried out using a Netzsch DSC 3500 Sirius, under the nitrogen atmosphere. The samples were heated from room temperature to $250^{\circ} \mathrm{C}$. After an isothermal step for 2 minutes, the samples were cooled down to $30^{\circ} \mathrm{C}$ and finally heated up to $250^{\circ} \mathrm{C}$ after another isothermal step for $2 \mathrm{~min}$. A scanning temperature ramp of $10 \mathrm{~K} / \mathrm{min}$ was used for all dynamic steps.

2.5.3. Thermogravimetric Analysis (TGA). The measurements were carried out using a Netzsch STA 2500. The samples were heated from room temperature to $600^{\circ} \mathrm{C}$, under the nitrogen atmosphere. A scanning temperature ramp of $10 \mathrm{~K} / \mathrm{min}$ was used for the dynamic steps.

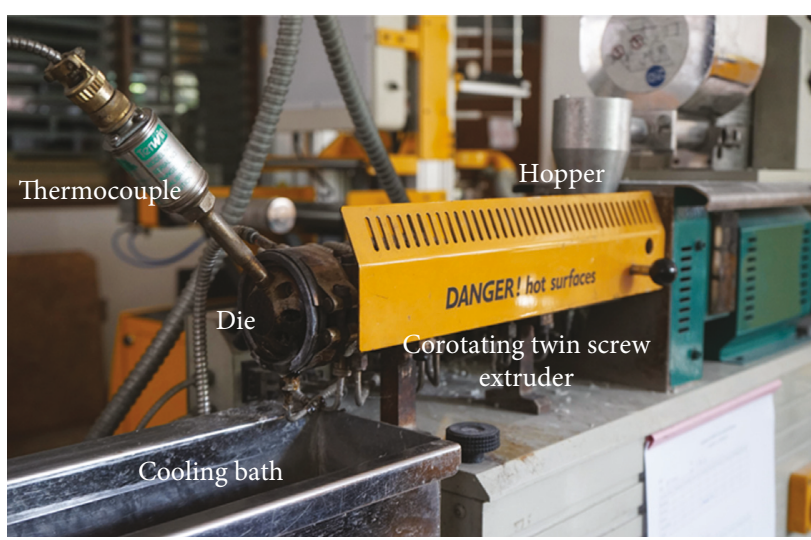

Figure 1: Melt extrusion process setup for ABS/GO composite filament fabrication.

TABLE 1: Parameters used for the FFF $3 \mathrm{D}$ printing of $\mathrm{ABS}$ and ABS/GO composites.

\begin{tabular}{lc}
\hline Parameters & Value \\
\hline Print nozzle diameter $(\mathrm{mm})$ & 0.4 \\
Nozzle temperature $\left({ }^{\circ} \mathrm{C}\right)$ & 220 \\
Bed temperature $\left({ }^{\circ} \mathrm{C}\right)$ & 100 \\
Layer height $(\mathrm{mm})$ & 0.1 \\
Print infill $(\%)$ & 100 \\
Print speed $(\mathrm{mm} / \mathrm{s})$ & 20 \\
\hline
\end{tabular}

2.5.4. Melt Flow Rate. The melt flow rate (MFR) is a common rheological measurement in which the molten polymer is pushed through a capillary die under a specific load, and the mass of extruded polymer is measured and reported in the unit of the extruded mass/10 minutes. The MFR measurements were carried out according to ASTM D1238 standard (Procedure A), at a temperature range of 220 $240^{\circ} \mathrm{C}$ with an applied load of $2.16 \mathrm{~kg}$ [22].

A pseudo-MFR measurement was performed using the FFF 3D printer with the nozzle diameter of $0.4 \mathrm{~mm}$ in order to determine the proper printing temperature. The extruded material through the nozzle in a 30-second time frame was weighed as a function of temperature.

2.5.5. Rheology Test. The linear viscoelasticity responses of the materials were measured using a parallel plate rheometer (ARES G2000). A frequency sweep between 0.0628 and $628 \mathrm{rad} / \mathrm{s}$ was performed at a temperature of $210^{\circ} \mathrm{C}$. Based on the result of the strain sweep test, a constant strain was fixed as $5 \%$ where the linear viscoelastic behavior maintained. Also, the steady shear measurements were conducted at $220^{\circ} \mathrm{C}$, from the shear rate range of 0.01 to $1000 \mathrm{~s}^{-1}$. The two parallel plates were set up at $1 \mathrm{~mm}$ gap for all measurements.

2.5.6. Tensile Test. To study the mechanical properties, the tensile test specimens were printed based on ASTM D638 Type- $\mathrm{V}$ geometry [23]. The crosshead speed was set as $5 \mathrm{~mm} / \mathrm{min}$. Ultimate tensile strength, Young's modulus, and elongation at break were evaluated as an average value of at least three replicates. 


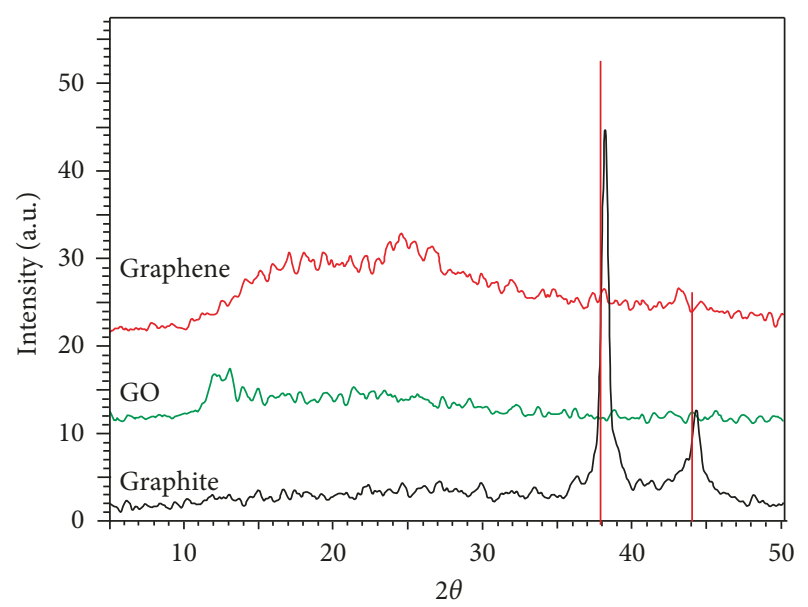

FIGURE 2: XRD diagram of graphite, graphene, and graphene oxide (GO).

\section{Results and Discussion}

Recently graphene/polymer composite has been fabricated by introducing graphene flakes into a conventional polymer that can be used for FFF printing applications. However, the apparent graphene aggregation and the phase separation between graphene and polymer matrixes are significant problems. In this work, graphene oxide (GO) was used to improve the graphene's dispersion in the ABS matrix.

3.1. X-Ray Diffraction (XRD) Analysis. In this study, GO was obtained by the oxidation of graphite regarding Hummers' method. Figure 2 shows the XRD patterns of the graphite, graphene, and obtained GO.

According to Bragg's law $(n \lambda=2 d \sin \theta)$, the value of $\mathrm{D}$ spacing depended on the $\theta$ value. The diffraction peak of graphite was observed at $2 \theta=36.7^{\circ}$ with $\mathrm{D}$ spacing around $0.11 \mathrm{~nm}$. The diffraction peak for graphene was shifted to $2 \theta$ $=25$ with $\mathrm{D}$ spacing around $0.35 \mathrm{~nm}$ as compared to those of graphite, while the GO revealed the diffraction peak at $2 \theta=$ $12.9^{\circ}$ with $\mathrm{D}$ spacing of $0.67 \mathrm{~nm}$. The shifts of the diffraction peak and the increase of the $\mathrm{D}$ spacing value attributed to the oxygen functional group between planes of GO sheets. The interactions of the oxygen functional group between GO interlayers led to an increase in the $\mathrm{D}$ spacing value, while the $\theta$ value decreased. In other words, in the absence of the oxygen functional group, the $\theta$ value increases, while the $\mathrm{D}$ spacing value decreases.

3.2. Thermal Properties. Figure 3 shows the representative DSC curves of ABS, ABS/GO (dry mixing), and ABS/GO (solvent mixing) composite filaments. In general, the variation in the melting temperature $\left(T_{\mathrm{m}}\right)$ indicated the change in crystal structures of material. $T_{\mathrm{m}}$ of nanocomposites could be changed upon filler loading. ABS has no exact melting point because of its amorphous characteristic. However, no significant difference between $T_{\mathrm{g}}$ of the neat ABS filament and the ABS/GO composite filaments from both dry mixing and solvent mixing methods was found. The glass transition

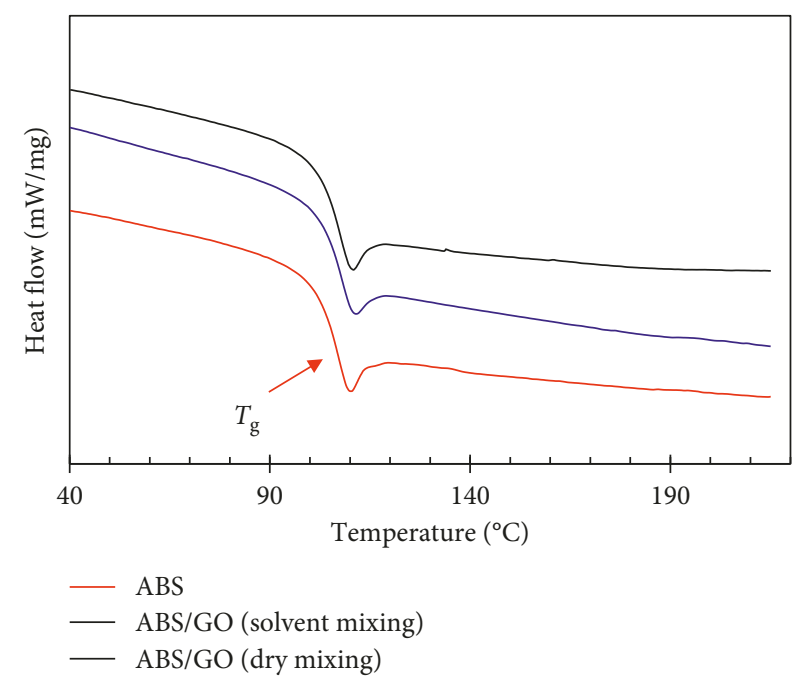

Figure 3: Melting temperature of the ABS filament, ABS/GO (solvent mixing), and ABS/GO (dry mixing) composite filaments from the DSC second heating scan.

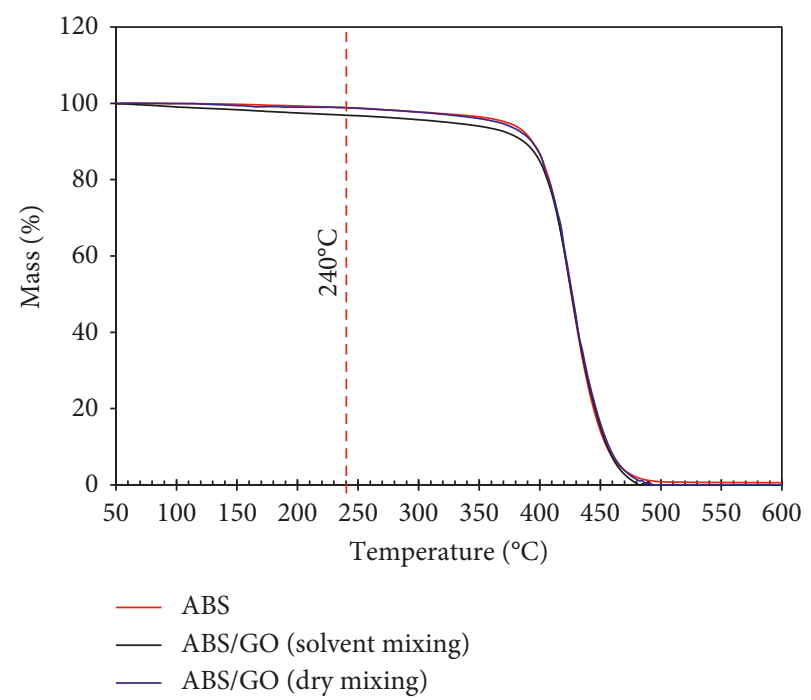

Figure 4: TGA thermogram of the ABS filament, ABS/GO (solvent mixing), and ABS/GO (dry mixing) composite filaments.

temperatures $\left(T_{\mathrm{g}}\right)$ were observed at $105.72^{\circ} \mathrm{C}, 104.77^{\circ} \mathrm{C}$, and $105.69^{\circ} \mathrm{C}$ for $\mathrm{ABS}, \mathrm{ABS} / \mathrm{GO}$ (dry mixing), and $\mathrm{ABS} / \mathrm{GO}$ (solvent mixing) filaments, respectively. The maintained $T_{\mathrm{g}}$ subsequently revealed the thermal stability of the ABS/GO composite even though the composite experienced the solvent system before the extrusion process. Furthermore, the ABS/GO composite could be softened and possibly $3 \mathrm{D}$ printed using the same temperature setup used for the pure and conventional ABS filaments.

3.3. Thermal Stability. To explore the effect of GO on thermal stability of the ABS and ABS/GO composite filaments, thermal gravimetric analysis (TGA) was conducted. Figure 4 shows the TGA thermogram of neat ABS and ABS/GO composite (2 wt.\% GO) filaments. All materials 


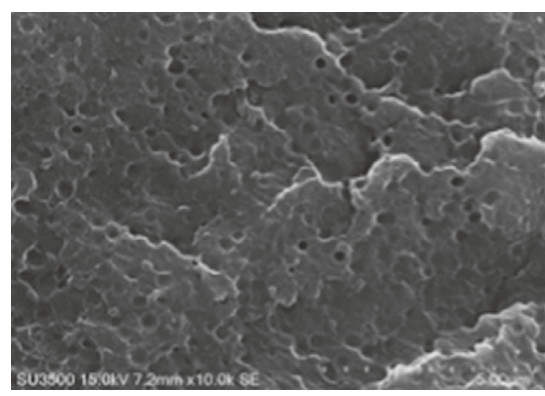

(a)

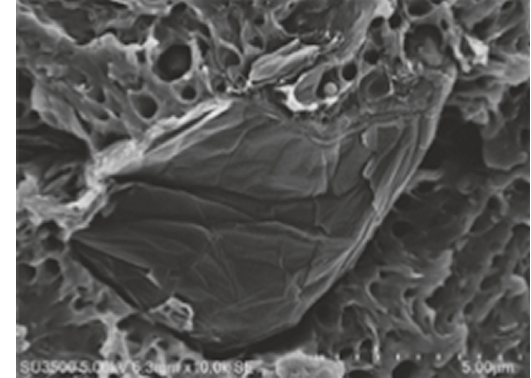

(b)

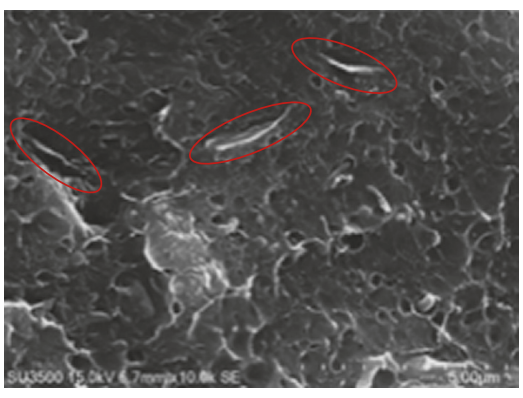

(c)

FIgURE 5: SEM images of (a) ABS, (b) ABS/GO (dry mixing), and (c) ABS/GO (solvent mixing) composite filaments.

started to decompose at the temperature around $400^{\circ} \mathrm{C}$, which was higher than the typical temperature for $3 \mathrm{D}$ printing the conventional ABS filament $\left(220-240^{\circ} \mathrm{C}\right)$. At $240^{\circ} \mathrm{C}$, the highest temperature used for the $3 \mathrm{D}$ printing the conventional ABS filament, the ABS/GO (solvent mixing) showed a more mass drop $(\sim 3 \%)$ as compared to the pure ABS ( 1.3\%) and ABS/GO (dry mixing). These results could be due to the volatile compounds and the solvent molecules that might still be trapped in the composite filaments.

3.4. Morphology. The alternative performance of graphenebased nanofiller-reinforced composites depends on the dispersion and distribution of graphene-based materials in the polymer matrix and the interfacial bonding between these two phases [16]. The microstructures of the cryofractured sections of ABS, ABS/GO (dry mixing), and ABS/GO (solvent mixing) on cross section are shown in Figure 5. Pure ABS showed a denser microstructure, while ABS/GO demonstrated a higher-porous surface with the presence of dispersed GO flakes embedded in the ABS matrix.

For ABS/GO, GO flakes with the dimensions around $10 \mu \mathrm{m}$ were noticed for the ABS/GO (dry mixing), while they ranged from $1-3 \mu \mathrm{m}$ for the ABS/GO (solvent mixing). The smaller size and the more uniform distribution of GO were the critical keys for enhancing the mechanical behavior and for the thermal diffusivity of the composite.

3.5. Flowability. The flowability of the ABS/GO composite was investigated via the melt flow rate (MFR) measurement. The MFR represented the flowability of the material and was inversely proportional to its viscosity. It could be used to evaluate how the presence of $\mathrm{GO}$ affected the processability of the ABS/GO composite. As shown in Figure 6, the MFR values of both $\mathrm{ABS}$ and $\mathrm{ABS} / \mathrm{GO}$ composite filaments increased with the temperatures, which meant the materials flew easier upon the temperature increased. The MFR values of the ABS/GO were lower than those of the pure ABS filament at all measured temperatures, which might be attributed to the solid GO flakes that restricted the mobility and disturbed the flowability of the ABS chains.

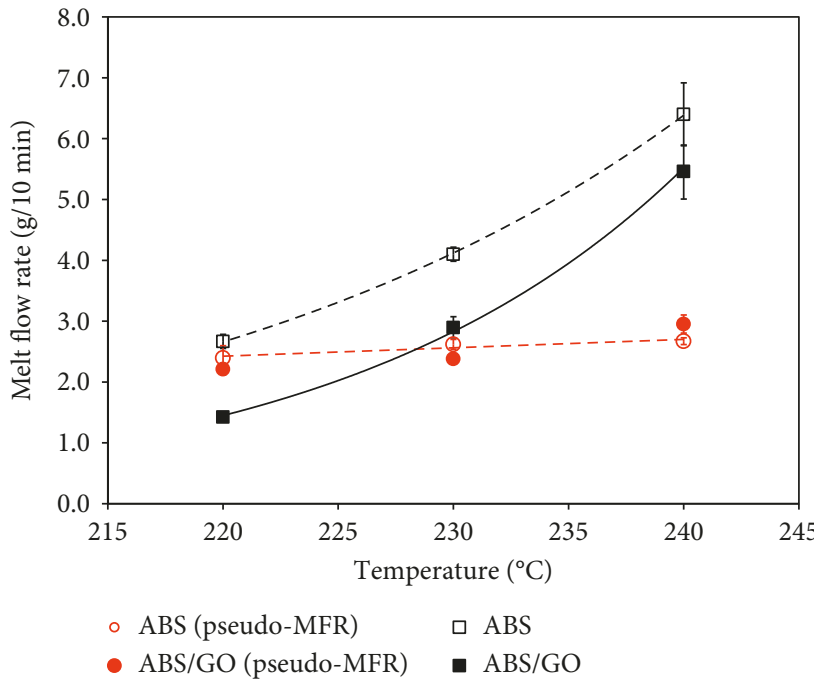

Figure 6: Melt flow rate (MFR) of the ABS filament and the ABS/GO composite filament dependent on temperature (220$240^{\circ} \mathrm{C}$ ). Black color represents the results from the conventional MRF measurement, and red represents the results from the pseudo-MFR measurement using the $3 \mathrm{D}$ printer.

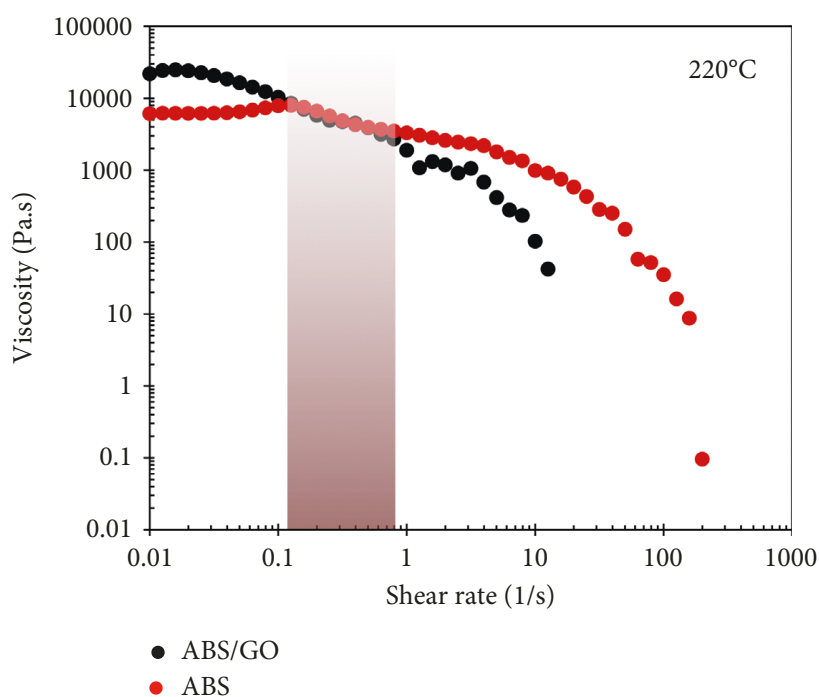

FIGURE 7: Shear rate dependence of viscosity for ABS and ABS/GO composite filaments. 


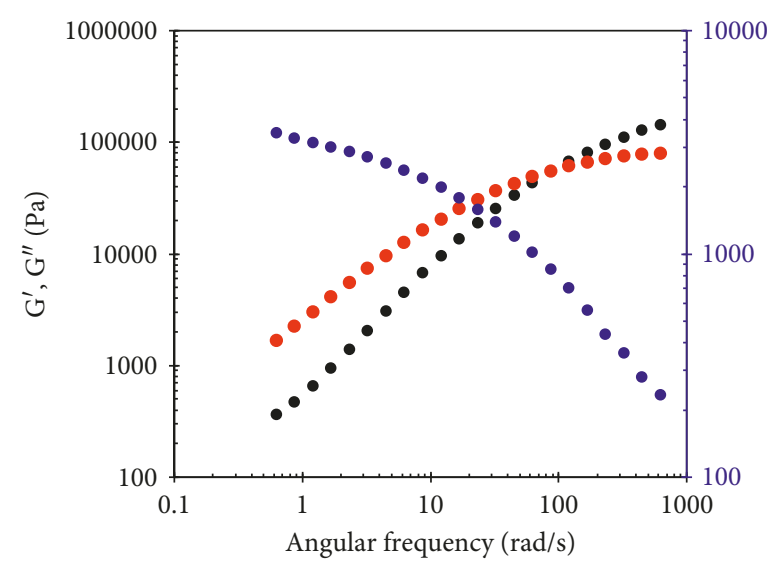

(a)

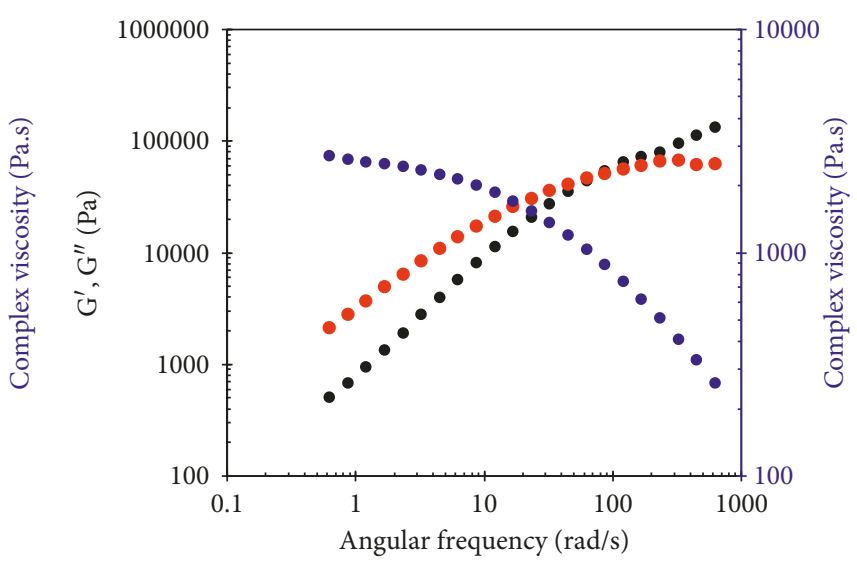

(b)

FIGURE 8: Rheological properties from the dynamic frequency sweep test: (a) ABS filament; (b) ABS/GO composite filament.

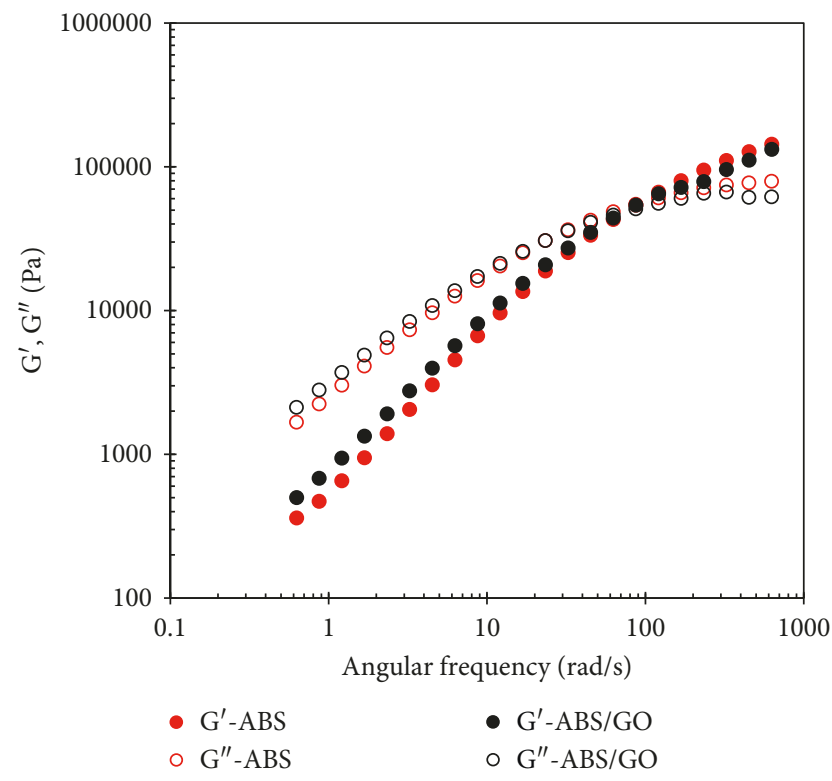

Figure 9: Storage modulus $\left(\mathrm{G}^{\prime}\right)$ and loss modulus $\left(\mathrm{G}^{\prime \prime}\right)$ versus the angular frequency for $\mathrm{ABS}$ filament and ABS/GO composite filament.

For FFF 3D printing processes, knowing the extrusion temperatures and flowability of the printed materials led to the more accuracy and precision of the printing process. The MFR information can be used as a guideline for setting up the printing parameters [24]. In this study, a pseudo-MFR measurement was conducted by measuring the extruded mass of the filaments through the printer nozzle. The pure $\mathrm{ABS}$ and $\mathrm{ABS} / \mathrm{GO}$ filaments displayed clear plateau values at all temperatures (Figure 6). As a result, the edge of the plateau reflected the lower bound of acceptable temperature for the corresponded extrusion rate. Theoretically, below this temperature, the mass of polymer extruded cannot be accurately achieved at the given feed rate.

On the contrary, extruding at a higher temperature than the lower bound is undesirable since it would lead to slower solidification of the extruded bead on the printed part. It was

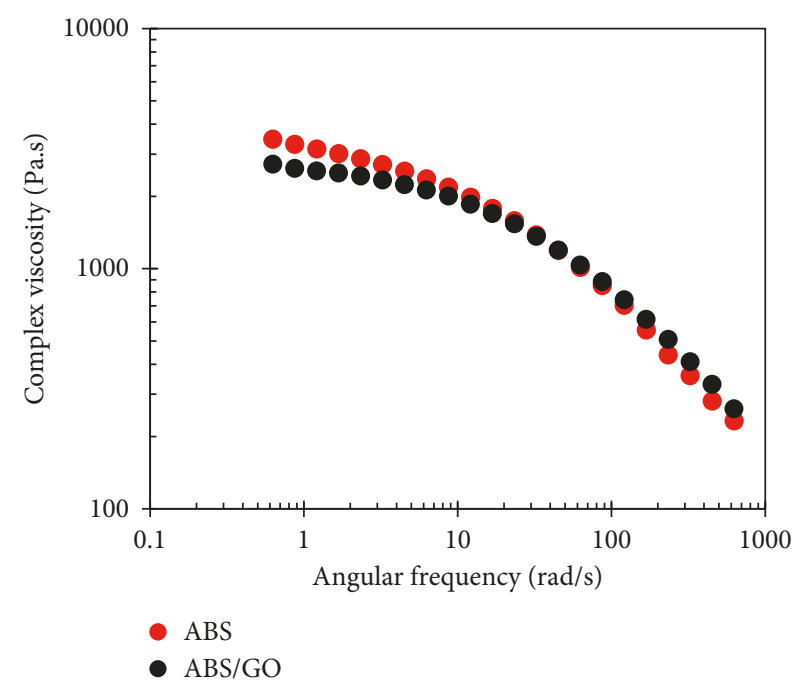

FIgURE 10: Complex viscosity versus the angular frequency for the ABS filament and the ABS/GO composite filament.

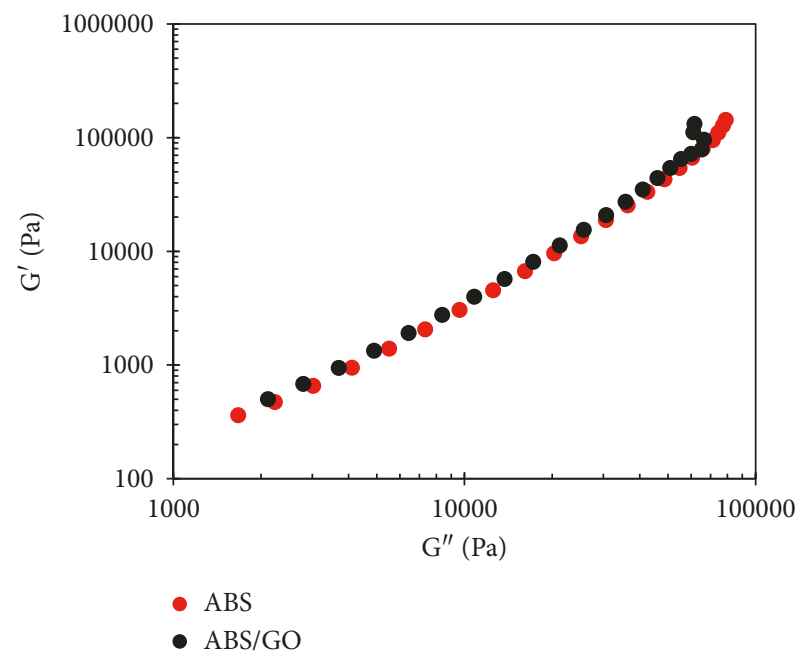

FIgURE 11: $G^{\prime}$ versus $G^{\prime \prime}$ plot for (red) ABS filament and (black) ABS/GO composite filament. 


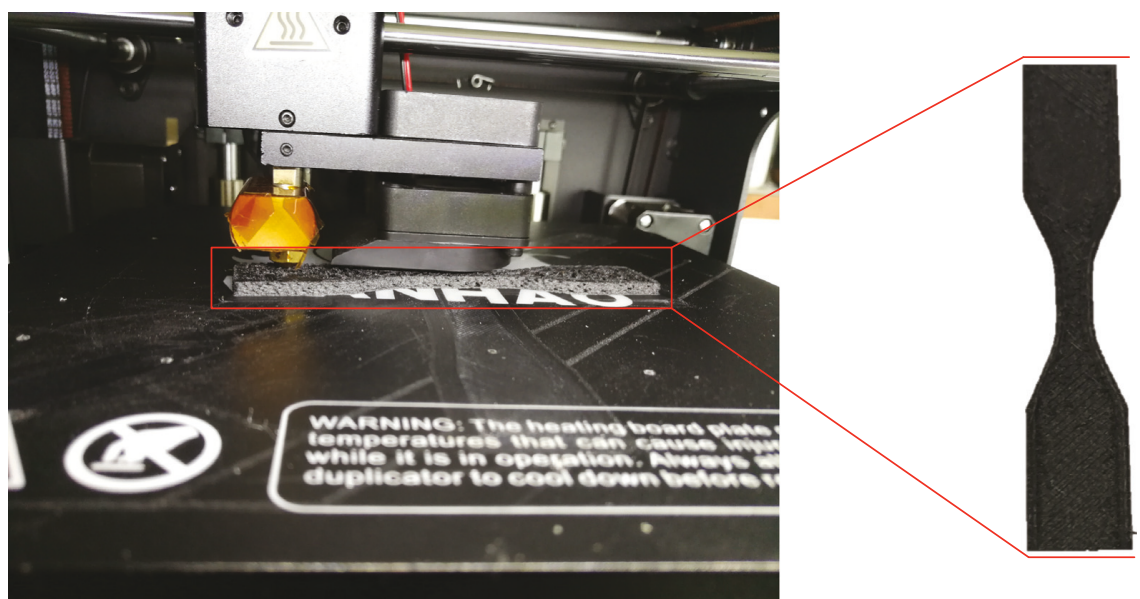

Figure 12: FFF 3D printed specimen from the ABS/GO composite filament.

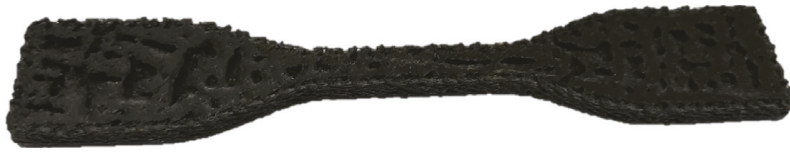

(a)

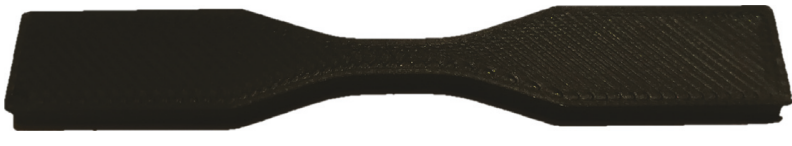

(b)

FIGURE 13: FFF 3D printed specimen from (a) ABS/GO (dry mixing) and (b) ABS/GO (solvent mixing) composite filaments.

found that the ABS/GO composite filament exhibited the similar behavior as compared to the pure ABS. Thus, $\mathrm{ABS} / \mathrm{GO}$ could be printed using the same temperature range $\left(220-240^{\circ} \mathrm{C}\right)$ used for the pure or conventional ABS filaments.

3.6. Rheological Properties. The average shear rate in typical twin-screw extrusion ranges between 1 and $1,000 \mathrm{~s}^{-1}$ $[25,26]$. For the FFF 3D printer, the shear rates in the nozzle are commonly in the range of $0.1-200 \mathrm{~s}^{-1}$ [27]. Figure 7 shows the shear rate dependence of viscosity for $\mathrm{ABS}$ and $\mathrm{ABS} / \mathrm{GO}$ at $220^{\circ} \mathrm{C}$. At the shear rate of 0.1 to $1 \mathrm{~s}^{-1}$, $\mathrm{ABS}$ and $\mathrm{ABS} / \mathrm{GO}$ filaments showed almost similar viscosity values, which confirmed that ABS/GO could be $3 \mathrm{D}$ printed with the same temperature setup for pure ABS. Incorporating with the MFR results, it was concluded that $\mathrm{ABS} / \mathrm{GO}$ and pure $\mathrm{ABS}$ could be $3 \mathrm{D}$ printed using the same printing parameters (nozzle temperature and print speed).

Interfacial interaction between GO and ABS is a crucial role for enhancing the mechanical performance of the composite. Generally, the opposition between particleparticle interaction and particle-polymer interaction can be used to determine the particle dispersion or aggregation in nanocomposites. Thus, rheological behavior becomes a useful tool to evaluate the dispersion and distribution of the GO in ABS. Because the rheological behaviors deliver the relation between molecular structure and mesoscale properties (such as phase structure and filler dispersion), at the same time, providing the processing properties [28, 29]. From the dynamic frequency sweep measurements, it was noticed that the rheological behaviors of ABS and ABS/GO were almost similar as shown in Figures 8-10, respectively.

Figure 9 presents the storage and loss moduli of ABS and ABS/GO filaments. Only a small deviation of the $G^{\prime}$ and $G^{\prime \prime}$ values was observed between ABS and ABS/GO filaments. Even though the increase in complex viscosities at low frequencies due to the effect of GO fillers was found, the complex viscosities of $\mathrm{ABS}$ and $\mathrm{ABS} / \mathrm{GO}$ filament remained almost the same values at higher rates as shown in Figure 10. This is again confirmed that the GO loading did not affect the viscosity or flowability of the ABS.

Furthermore, we created the $G^{\prime}-G^{\prime \prime}$ plot for predicting the dispersion of GO in ABS as presented in Figure 11. The $G^{\prime}-G^{\prime \prime}$ patterns of pure $A B S$ and $A B S / G O$ were close together, suggested the well distribution of $\mathrm{GO}$ in the composite.

3.7. FFF 3D Printability. Figures 12 and 13 present the WANHAO Duplicator 6, the 3D printer based on the FFF principle, and the printed $\mathrm{ABS} / \mathrm{GO}$ tensile specimens, respectively. With the same printing conditions used for pure ABS, the ABS/GO composite has been successfully printed. However, the clogged nozzle was sometimes observed, which further led to the print failure (Figure 13(a)).

3.9. Mechanical Properties. The tensile properties at the room temperature of $\mathrm{ABS}$ and $\mathrm{ABS} / \mathrm{GO}$ were investigated and presented in Figure 14. From the typical stress-strain tensile curves and corresponding statistical data, the elongation at the break value decreased with the GO loading. The 


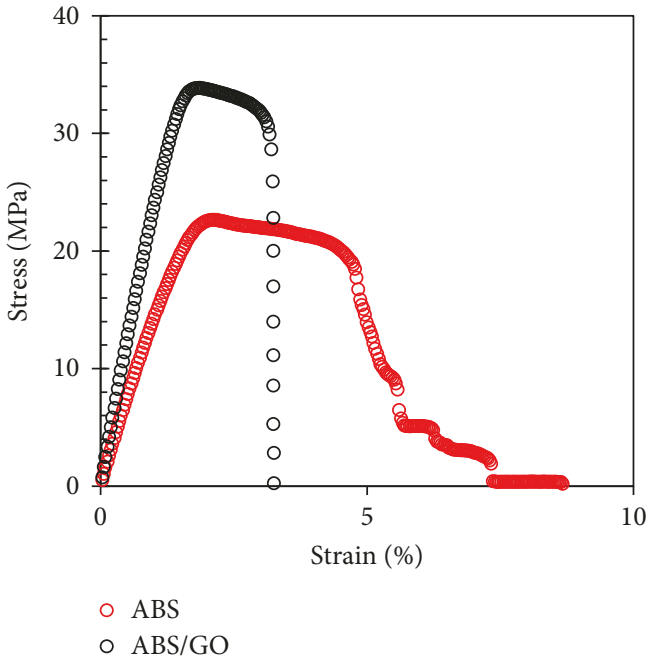

(a)

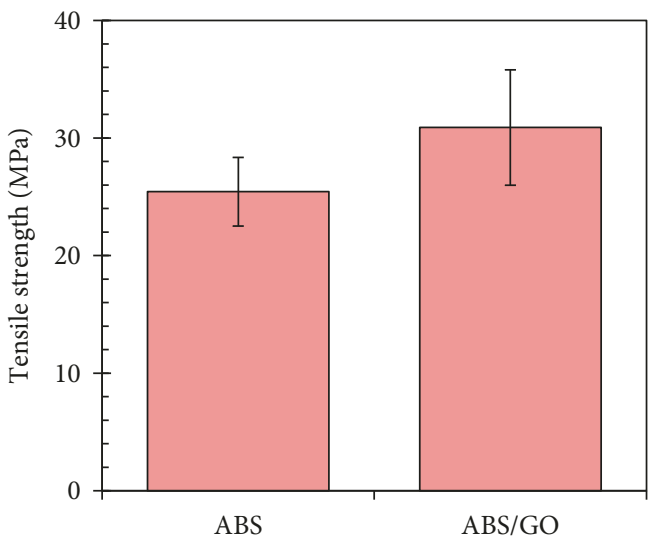

(c)

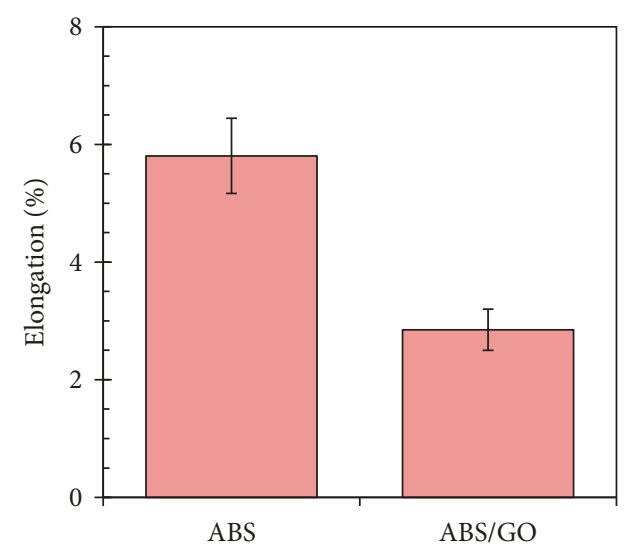

(b)

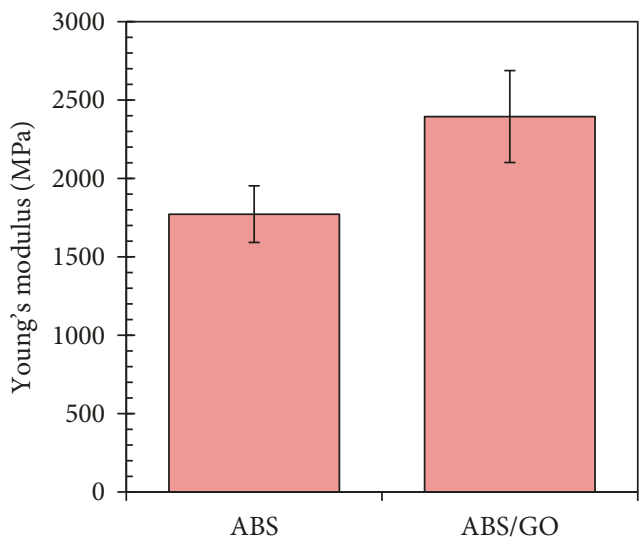

(d)

FIgURE 14: Typical stress-strain curves (a), value of elongation at break (b), tensile strength (c), and Young's modulus (d) of ABS and ABS/GO printed specimens.

elongation at the break value of pure ABS was determined as $5.8 \%$, while the value of $\mathrm{ABS} / \mathrm{GO}$ composite was $2.9 \%$. However, by adding 2 wt.\% GO, the tensile strength and Young's modulus of ABS were enhanced. This might be due to the interlayer crosslinks of GO sheets under loads, leading to the ordering of the hierarchical structures which results in the great significant enhancement of the mechanical properties [30].

\section{Conclusion}

A new 3D printing filament from ABS/GO composite was successfully prepared by solution mixing and followed by melted extrusion using a twin-screw extruder. The solvent system improved the GO dispersion capability in the ABS matrix and had no significant effect on the thermal properties of the ABS/GO composite. However, the aggregation of GO could lead to the die clogging and failure of the extrusion process. The tensile strength and Young's modulus of ABS were enhanced naturally by GO. Besides, the elongation at break decreased and needed to be further improved. Improving mechanical properties verified the feasibility of 3D printed ABS/GO for potential use in engineering applications.

Our study demonstrated one of the active attempts to print GO-based composite using FFF 3D printing process directly. However, the printed part quality, functionalities, and applications based on the printed ABS/GO composite needed to be further exploited.

\section{Data Availability}

The data used to support the findings of this study are available from the corresponding author upon request.

\section{Conflicts of Interest}

The authors declare that they have no conflicts of interest.

\section{Acknowledgments}

We thank Sami Briti from Polytech Montpellier, France, for helping in the preparation of graphene oxide (GO). 
Additionally, we thankfully acknowledge the financial support from grants for Development of New Faculty Staff, Ratchadaphiseksomphot Endowment Fund, Chulalongkorn University, and the Thailand Research Fund (TRG6180009).

\section{References}

[1] S. Hertle, M. Drexler, and D. Drummer, "Additive manufacturing of poly(propylene) by means of melt extrusion," Macromolecular Materials and Engineering, vol. 301, no. 12, pp. 1482-1493, 2016.

[2] A. Bandyopadhyay, F. Janas, and R. Van Weeren, "Processing of piezocomposites by fused deposition technique," in Proceedings of Tenth IEEE International Symposium on Applications of Ferroelectrics, pp. 999-1002, East Brunswick, NJ, USA, August 1996.

[3] T. F. McNulty, F. Mohammadi, A. Bandyopadhyay, D. J. Shanefield, S. C. Danforth, and A. Safari, "Development of a binder formulation for fused deposition of ceramics," Rapid Prototyping Journal, vol. 4, no. 4, pp. 144-150, 1998.

[4] X. Wang, M. Jiang, Z. Zhou, J. Gou, and D. Hui, "3D printing of polymer matrix composites: a review and prospective," Composites Part B: Engineering, vol. 110, pp. 442-458, 2017.

[5] J. F. Christ, N. Aliheidari, A. Ameli, and P. Pötschke, "3D printed highly elastic strain sensors of multiwalled carbon nanotube/thermoplastic polyurethane nanocomposites," Materials and Design, vol. 131, pp. 394-401, 2017.

[6] J. Zhang, Y. Yang, F. Fu, F. You, X. Dong, and M. Dai, "2017_ Zhang_resistivity and its anisotropy characterization of 3D printed acrylonitrile butadiene styrene copolymer-carbon black composites," Applied Sciences, vol. 7, no. 1, p. 20, 2017.

[7] R. Singh, G. Sandhu, R. Penna, and I. Farina, "Investigations for thermal and electrical conductivity of ABS-graphene blended prototypes," Materials, vol. 10, no. 8, p. 881, 2017.

[8] U. Kalsoom, P. N. Nesterenko, and B. Paull, "Recent developments in 3D printable composite materials," RSC Advances, vol. 6, no. 65, pp. 60355-60371, 2016.

[9] S. J. Kalita, S. Bose, H. L. Hosick, and A. Bandyopadhyay, "Development of controlled porosity polymer-ceramic composite scaffolds via fused deposition modeling," Materials Science and Engineering: C, vol. 23, no. 5, pp. 611-620, 2003.

[10] A. M. Pinto, J. Cabral, D. A. P. Tanaka, A. M. Mendes, and F. D. Magalhaes, "Effect of incorporation of graphene oxide and graphene nanoplatelets on mechanical and gas permeability properties of poly(lactic acid) films," Polymer International, vol. 62, no. 1, pp. 33-40, 2012.

[11] B. E. Yamamoto, A. Z. Trimble, B. Minei, and M. N. G. Nejhad, "Development of multifunctional nanocomposites with 3-D printing additive manufacturing and low grapene loading," Journal of Thermoplastic Composite Materials, pp. 1-26, 2018.

[12] H. Kim and C. W. Macosko, "Processing-property relationships of polycarbonate/graphene composites," Polymer, vol. 50, no. 15, pp. 3797-3809, 2009.

[13] X. Wei, D. Li, W. Jiang et al., "3D printable graphene composite,” Scientific Reports, vol. 5, no. 1, pp. 1-7, 2015.

[14] C. Wang, Y. Li, G. Ding, X. Xie, and M. Jiang, "Preparation and characterization of graphene oxide/poly(vinyl alcohol) composite nanofibers via electrospinning," Journal of Applied Polymer Science, vol. 127, no. 4, pp. 3026-3032, 2013.
[15] X. Lin, X. Shen, Q. Zheng et al., "Fabrication of highly-aligned, conductive, and strong graphene," ACS Nano, vol. 6, no. 12, pp. 10708-10719, 2012.

[16] V. Panwar and K. Pal, “An optimal reduction technique for rGO/ABS composites having high-end dynamic properties based on Cole-Cole plot, degree of entanglement and C-factor," Composites Part B: Engineering, vol. 114, pp. 46-57, 2017.

[17] D. Zhang, B. Chi, B. Li et al., "Fabrication of highly conductive graphene flexible circuits by 3D printing," Synthetic Metals, vol. 217, pp. 79-86, 2016.

[18] S. Dul, L. Fambri, and A. Pegoretti, "Fused deposition modelling with ABS-graphene nanocomposites," Composites Part A: Applied Science and Manufacturing, vol. 85, pp. 181191, 2016.

[19] V. Panwar and K. Pal, "Dynamic performance of an amorphous polymer composite under controlled loading of reduced graphene oxide based on entanglement of filler with polymer chains," Journal of Polymer Research, vol. 25, no. 2, 2018.

[20] S. Chen, J. Lu, and J. Feng, "3D-Printable ABS blends with improved scratch resistance and balanced mechanical performance," Industrial and Engineering Chemistry Research, vol. 57, no. 11, pp. 3923-3931, 2018.

[21] E. A. Papon and A. Haque, "Tensile properties, void contents, dispersion and fracture behaviour of $3 \mathrm{D}$ printed carbon nanofiber reinforced composites," Journal of Reinforced Plastics and Composites, vol. 37, no. 6, pp. 381-395, 2018.

[22] ASTM International, ASTM D1238-13, ASTM Int., West Conshohocken, PA, USA, 2013.

[23] American Society for Testing and Material (ASTM), Standard Test Method for Tensile Properties of Plastics (D638-14), ASTM Int., West Conshohocken, PA, USA, 2014.

[24] T. Pfeifer, C. Koch, L. Van Hulle, G. A. M. Capote, and P. Natalie, "Optimization of the FDM additive manufacturing process," in Proceedings of SPE ANTEC Indianapolis, pp. 22-29, Indianapolis, IN, USA, May 2016.

[25] T. A. Osswald and N. Rudolph, Polymer Rheology Fundamental and Applications, Hanser Publishers, Munich, Germany, 2015.

[26] N. Venkataraman, S. Rangarajan, M. J. Matthewson et al., "Feedstock material property-process relationships in fused deposition of ceramics (FDC)," Rapid Prototyping Journal, vol. 6, no. 4, pp. 244-253, 2000.

[27] L. A. Al-Hariri, B. Leonhardt, M. Nowotarski, J. Magi, and K. Chambliss, Carbon Nanotubes and Graphene as Additives in 3D Printing, INTECH, London, UK, 2016.

[28] L. Du, M. Namvari, and F. J. Stadler, "Large amplitude oscillatory shear behavior of graphene derivative/polidimethylsiloxane nanocomposites," Rheologica Acta, vol. 57, no. 5, pp. 429-443, 2018.

[29] G. M. Shin, J. Y. Park, and Y. C. Kim, "GO dispersion and mechanical properties of 70PC/30ABS/GO composites according to fabrication methods," Polymer Korea, vol. 41, no. 3, pp. 452-459, 2017.

[30] R. Sharma, R. Singh, R. Penna, and F. Fraternali, "Investigations for mechanical properties of Hap, PVC and PP based 3D porous structures obtained through biocompatible FDM filaments," Composites Part B: Engineering, vol. 132, pp. 237-243, 2018. 


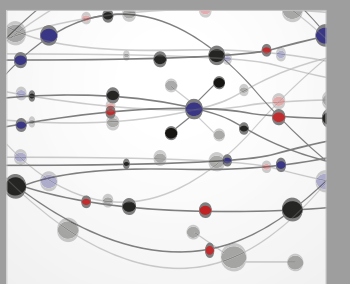

The Scientific World Journal
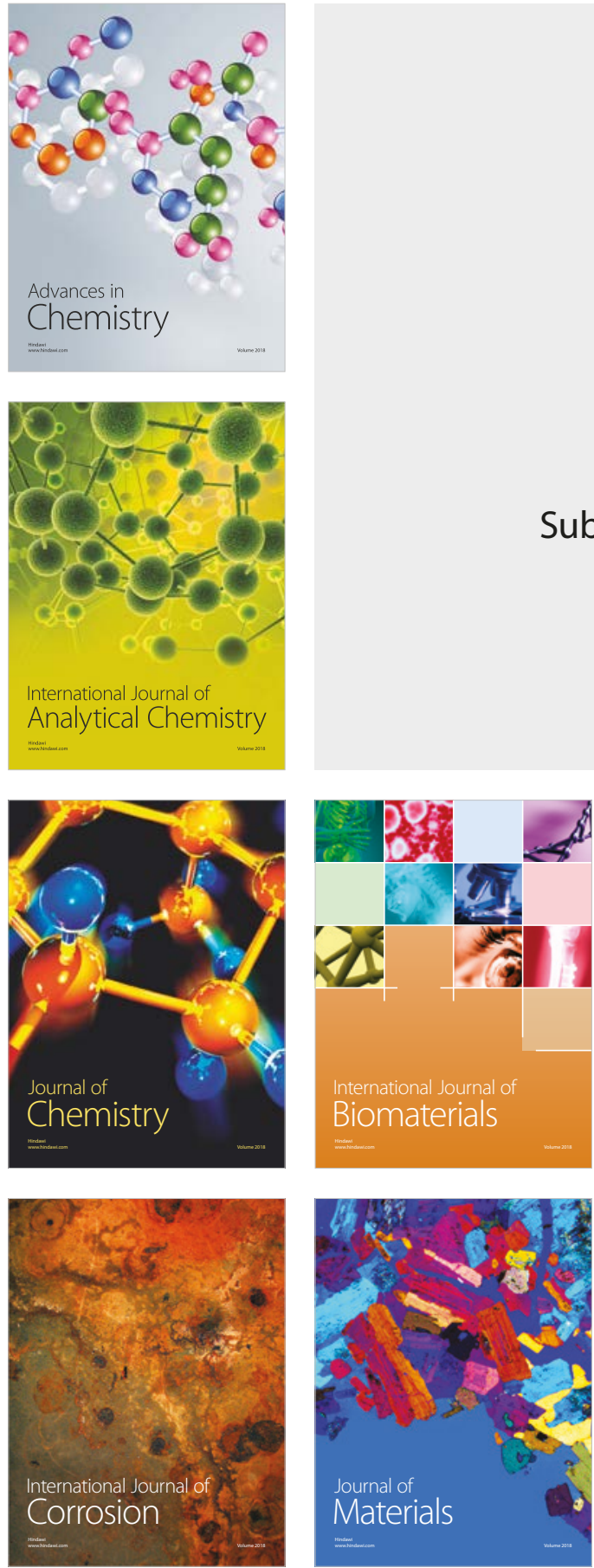

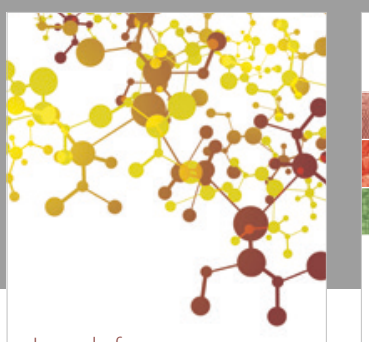

Journal of

Applied Chemistry
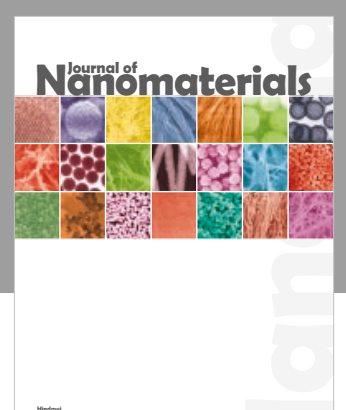

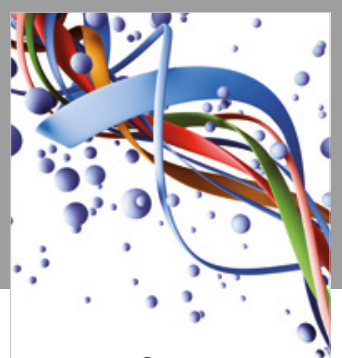

Scientifica

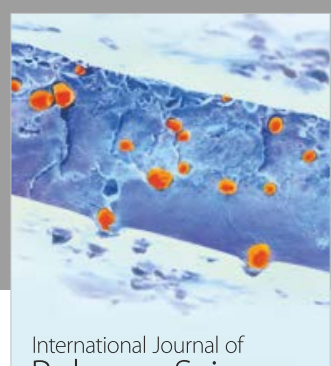

Polymer Science

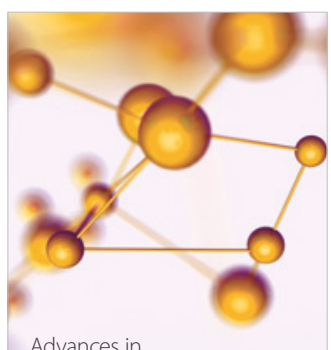

Physical Chemistry
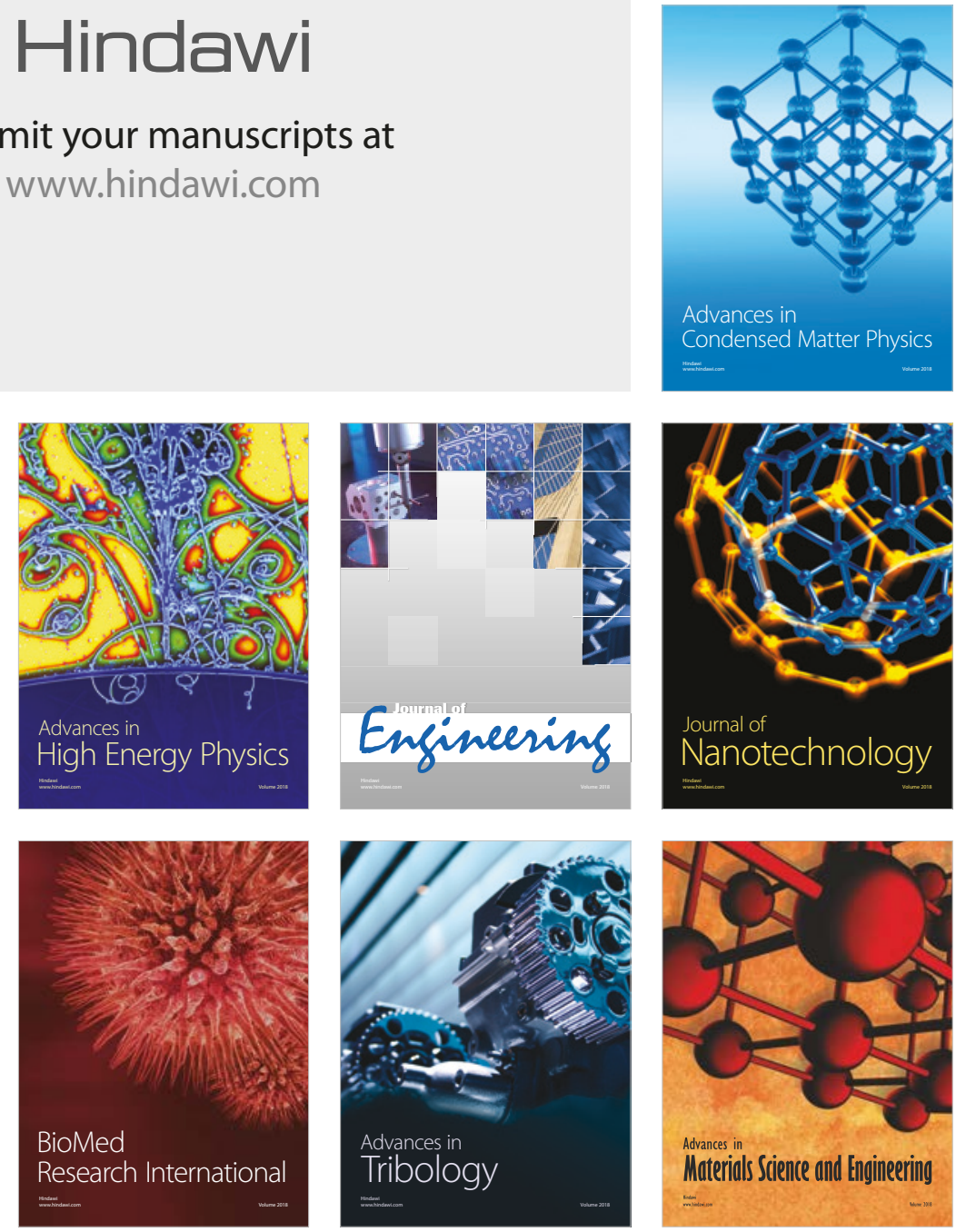